\title{
As reformas do ensino secundário: as lições das transferências Norte-Sul
}

The reforms of secondary education: the lessons of the North-South transfers

Abdeljalil Akkari ${ }^{1}$

\section{Resumo}

Este texto busca discutir o recente desenvolvimento da escolarização secundária em nível internacional. Ele se preocupa particularmente com a educação secundária no sistema educacional. 0 artigo discute os empréstimos e transferências de modelos de educação secundária entre os países do Norte e do Sul. Por fim, o texto enfatiza a importância de um melhor treinamento dos professores com o objetivo de aperfeiçoar a qualidade da educação secundária.

Palavras-chave: Educação Comparada; Escolarização Secundária;

Desenvolvimento do Aprendizado Profissional; Desenvolvimento Profissional;

Treinamento de Professores

\section{Abstract}

This text aims to discuss the recent development of secondary schooling on the international level. It points out in particular the place of secondary education in the educational system. Borrowing and transferring models of secondary education between the North and the South will be discussed. Lastly, it stresses the importance of better training of the teachers to improve quality of secondary education.

Keywords: Comparing Education; Secondary Schooling; Evolving of Professional Learning; Professional Development; Teachers Training

1 Professor e Diretor de Pesquisa do Haute École Pédagogique Berne-Jura-Neuchâtel (Bienne, Suíça). E-mail: akkari.abdeljalil@hep-bejune.ch. 
O objetivo deste texto, e também sua maior dificuldade, reside em uma tentativa de se lançar um breve olhar sobre um tema complexo que são os méritos e as fraquezas do ensino secundário. Após uma pequena parte introdutória sobre o espaço do ensino secundário no modelo escolar, nós apresentaremos, em um segundo momento, as diferentes e atuais transferências de modelos de desenvolvimento do ensino secundário, entre o Norte e o Sul. Na terceira parte, levantaremos um balanço sutil do advir do ensino secundário nos países do Sul. Analisaremos, em particular, a necessidade de aumentar a profissionalização dos educadores do ensino secundário.

\section{O lugar do ensino secundário dentro do modelo escolar}

O modelo escolar encontra-se em progressivo desenvolvimento na Europa; mas não era assim até o final do século XIX, quando ele tornouse um dado estrutural na vida sociocultural. Com efeito, a instauração da escolaridade obrigatória provocou uma revolução cultural profunda. A escola era introduzida para substituir "a hereditariedade" como modalidade de reprodução social. A partir da instauração da escolaridade obrigatória, o espaço ocupado pelo ensino secundário foi marginalizado, em termos efetivos no sistema escolar dos países europeus no fim do século XIX. O objetivo principal era escolarizar o maior número de crianças na escola primária a fim de preparar os futuros cidadãos para exercer plenamente seus potenciais democráticos. Se a importância quantitativa do ensino secundário era pequena, ela não permanecia menor no nível da transição que ele assegurava entre o primário e a universidade e, também, no nível de formação dos educadores.

Às vésperas da Segunda Guerra Mundial, liceus e colégios na França não escolarizaram mais do que $5 \%$ a $6 \%$ de uma faixa etária. O restante da população era escolarizado no primário e nos cursos complementares. Essa organização, dividida em duas redes de ensino, socialmente discriminadas, uma conduzindo à universidade, a outra não, permaneceu até o fim dos anos 1950. Progressivamente, o ensino secundário tornou-se cada vez mais importante nos países do Norte. Assistimos então a uma massificação do primeiro ciclo do ensino secundário. Assim, durante um longo tempo, o ensino primário francês estava separado do ensino secundário. Somente uma minoria dos 
estudantes passava para o secundário ou prosseguia seus estudos depois dos 14 anos. A partir das reformas de 1959 e 1963, a parcela dos alunos que passavam do primário para o primeiro ciclo do secundário aumentou muito rapidamente; este último absorve progressivamente os alunos das faixas etárias entre 11 e 15 anos. A quase totalidade dos alunos seria finalmente escolarizada no primeiro ciclo secundário a partir do fim dos anos 1960 (BIHR; PFEFFERKORN, 1995).

A massificação do ensino secundário foi assim acelerada, sem que isso, contudo, levasse a sua democratização. A definição de democratização que se impôs entre as duas guerras é aquela da seleção, que permite aos alunos oriundos das categorias populares alcançar o ensino secundário. Trata-se de substituir a seleção por nascimento pela seleção por mérito. As contribuições da psicologia nos permitem adquirir ferramentas teóricas para compreender essa definição de democratização. A aposta é, então, favorecer uma orientação segundo as aptidões dos estudantes. Uma vez que a escola se impôs nos anos 1960 como um meio de ascensão social, tendo ela penetrado nas classes médias bem antes que fosse realizada a unificação do sistema de ensino, o fracasso escolar aparece como um problema social (ISAMBERT JAMATI, 1985). A sociologia da educação exprime o mito da democratização do ensino secundário. Trata-se mais de fazer um deslocamento de posições sociais do que uma verdadeira transformação dessas posições sociais.

No sistema escolar, o ensino secundário assume, portanto, um papel de transição entre a educação primária (de base) e o ensino superior. Ora, à medida que a massificação avança, essa posição do ensino se sedimenta, sendo ainda mais criticada. Assim, o ensino secundário aparenta estar em uma crise estrutural permanente. Essa crise é mediada por três fenômenos: o fracasso da democratização, o espaço das famílias populares no ensino secundário e o espaço do ensino técnico no ensino secundário.

Nesse debate, o desenvolvimento do ensino secundário não tem permitido romper a lógica das redes distintas que existem na escola. A escola "capitalista" se mantém dividida em redes de escolarização distintas destinadas a reproduzir a estrutura social desigual: uma rede curta primário-profissionalizante, destinada a crianças das classes populares e uma rede secundária superior para a educação prolongada das crianças da elite (BAUDELOT; ESTABLET, 1971). A massificação, no entanto, não acaba com o dualismo primário/secundário, sobre o qual se funda o modelo de ensino. 
No nível da relação escola-família, é preciso lembrar que historicamente a escola se construiu afastada e, por vezes, contra as famílias populares. Com a massificação escolar e, em particular, a forte entrada de todas as categorias sociais no ensino secundário, foi necessário associar a família ao êxito de seu filho. Ora, como sublinha Thin (1998), a questão das relações familiares populares com a escola não está reduzida à questão da escolarização. Está em jogo a confrontação entre os dois modos de socialização radicalmente opostos: o modo escolar, vivenciado e pensado como universal para os ensinos, e o modo popular. Para realizar o projeto de democratização, seria necessário, portanto, adaptar as estruturas do sistema escolar, suas formas de exercício da autoridade e suas práticas pedagógicas à aceitação de um público socialmente heterogêneo e indócil. Ora, o modelo de escola dominante no secundário permanece aquele de um saber acadêmico ao qual os alunos são confrontados sem serem verdadeiramente ajudados a compreender seus métodos, seus sentidos e suas finalidades. A cultura contemporânea repousa sobre uma hierarquização de saberes fundados sobre a valorização da abstração (CHARLOT; BAUTIER; ROCHEX, 1992).

É preciso ainda aumentar o debate sobre o ensino técnico no sistema educacional. Assim, o desenvolvimento do modelo escolar subtraiu uma grande parte da formação, dos trabalhadores, das corporações e com relação à aprendizagem informal. A escolarização dos trabalhadores tem inflamado o debate sobre a inadequação formação-emprego no secundário.

A análise crítica dos processos de desenvolvimento do ensino secundário que prevalece nos países do Norte não é aplicada nos países do Sul e, notadamente, naqueles que chamamos de países emergentes. Para o conjunto desses países, o ensino secundário se situa no coração do desenvolvimento dos recursos humanos por várias razões: não saber nem ler nem contar é uma "forma de deficiência"; uma educação secundária pode ajudar as pessoas a obterem um trabalho e ganhos suplementares, notadamente para as populações mais desfavorecidas; quanto mais uma população é escolarizada, mais preparada ela está para compreender e fazer valer seus direitos; isso é ainda mais verdadeiro para as mulheres. Está provado, em estudos internacionais, que a escolarização das mulheres tem um impacto direto sobre as taxas de fecundidade e a redução da mortalidade infantil. 
Um recente estudo da UNESCO e da OCDE constatou que, no curso dos últimos 20 anos, o investimento no capital humano representou um ponto e meio da taxa de crescimento anual de 16 economias emergentes. Entretanto, o acesso ao ensino secundário, condição indispensável ao surgimento de uma mão-de-obra instruída, evoluiu lentamente. Em 2002, os adultos dos 16 países emergentes passavam em média 7,6 anos na escola, ou seja, mais que o dobro do período registrado em 1960, que era de 3,4 anos. Esse número era, todavia, inferior em quase três anos da média dos países da OCDE, ou seja, 10,2 anos. No ritmo em que atualmente cresce a escolarização, será preciso ainda 30 anos para algumas dessas economias emergentes atingirem o número de anos de formação da zona OCDE atual. Segundo os autores do estudo, é na Argentina, no Chile, na Jamaica, na Malásia, no Peru, nas Filipinas e no Uruguai que a ligação entre educação e crescimento econômico foi mais estreita, no curso desses últimos 20 anos. Por exemplo, em 1960, os malasianos freqüentavam a escola durante 3,22 anos, em média, enquanto o PIB por habitante era de US\$2.000. Em 2000, a duração média da escolarização passou para 9,31 anos e o PIB por habitante havia triplicado, atingindo aproximadamente US $\$ 6.000$ (UNESCO/ISU-OCDE, 2003).

Os resultados eram menores no Egito, na Índia e na Tunísia, onde "os níveis de formação eram no início sensivelmente mais baixos" que nos outros países estudados. O capital humano representa tem papel muito importante no processo de crescimento econômico, uma vez que atingiu um certo limite crítico, e que uma forte escolarização no segundo ciclo secundário e no ensino superior representa muito sobre o crescimento econômico.

O ensino secundário adquiriu um espaço importante no sistema educacional dos países do Norte. Atualmente, os efetivos explodem nos países emergentes e, em um futuro próximo, uma massificação estará em marcha no restante dos países do Sul. Portanto, a natureza do ensino secundário é ainda frágil e raramente objeto de um consenso político ou pedagógico, já que alguns o relacionam voluntariamente à lógica do primário, enquanto que outros vêem seu papel como preparação para os ensinos técnico e superior.

Isso está claro no caso do Brasil, onde o ensino secundário é completamente dominado pela perspectiva de que os alunos têm que passar no vestibular. Ora, essa orientação é muito negativa, como afirma 
Charlot (2006, p. 18): "O modelo baseado em se assinalar uma alternativa, certa ou errada, verdadeira ou falsa, não mede a atividade intelectual."

\section{A tRANSFerÊnCIA de MOdelos COMO MÉtOdo de DESENVOLVIMENTO dO ENSINO SECUNDÁRIO NOS PAísES DO SUL}

Existe atualmente no mundo um interesse particular pela análise do movimento de transferência das idéias e das estruturas educacionais. Esse interesse pode ser explicado, por sua vez, pela integração política, social e econômica entre países e, mais ainda, pela tendência das policy makers em olhar para outra direção para encontrar soluções inovadoras para os problemas educacionais locais. A literatura anglofônica sobre a noção de transferência está atualmente em plena expansão (DOLOWITZ; MARSH, 1996). Entretanto, essa literatura sobre as transferências sofre de uma falta de clareza terminológica e teórica. Assim, a distinção entre política de transferência, difusão, lições a aprender (lesson drawing), aprender e tomar emprestado não está esclarecida. No mais, há uma tendência em focalizar os atores, os processos e os resultados em diferentes setores da educação, em detrimento da análise dos discursos políticos sobre as transferências.

Rose (1991) sugere cinco perspectivas sobre as lições a aprender (lesson drawing), em matéria de educação, inspirando-se naquilo que se passa em outros lugares e contextos: a cópia, a emulação, a hibridação, a síntese e a inspiração. As corporações internacionais podem, nesse caso, dar lugar a uma adoção total ou parcial desta ou daquela orientação tomada em outros contextos. A cópia (copying) implica uma adoção menor da identidade de um programa diferente. A avaliação prospectiva do contexto político e de outras variáveis, pertencente aos dois contextos, mostra um grande grau de compatibilidade. A perspectiva da emulação tenta acomodar as diferenças entre os dois lugares, remodelando um programa antes da sua adoção. A hibridação consiste em combinar uma série de elementos para preparar o programa educacional final para a transferência. Por exemplo, podemos observar que certos elementos importantes de um programa podem se apresentar inoperantes no contexto-alvo, mesmo se eles são apropriados no contexto original. O segmento apropriado ou inoperante pode ser transferido de uma terceira localização. A síntese consiste em uma combinação de elementos diferentes, de diferentes lugares, reunidos para formar uma opção distinta. É difícil, em geral, avaliar uma síntese de programas educacionais. Enfim, Rose (1991) propõe a 
inspiração como perspectiva possível. Ter uma nova perspectiva sobre um problema comum pode inspirar a reflexão à proposta de um programa ou de uma opção pedagógica. Os atores da educação podem encontrar a inspiração nas viagens e na observação. Trata-se, portanto, de uma perspectiva indireta.

O modelo de transferência proposto por Dolowitz e Marsh (1996) oferece um quadro conceitual adequado para a análise da transferência, em matéria de política educacional, ocorrendo ao mesmo tempo no interior de um país como também entre países. Ele é baseado na idéia de que a transferência é um processo: "[...] in which knowledge about policies, administrative arrangements, institutions etc. in one time or place is used in the development of policies, administrative arrangements and institutions in another time or place" (p. 3). ${ }^{2}$ Esse modelo faz a distinção entre os tipos e os níveis de transferência e entre os diferentes atores, a partir de uma série de questões: $\mathrm{O}$ que é uma política de transferência? $\mathrm{O}$ que ela transfere? Por que uma política é transferida e a partir de quais lições ela se inspira? Dolowitz e Marsh (1996) fornecem a lista dos atores e dos agentes implicados no processo de transferência: os eleitos, os partidos políticos, os burocratas, os grupos de pressão, experts, empresários e as instituições supranacionais.

Em outros estudos sobre a transferência, encontramos outras noções: apropriação, difusão, cópia (copying) e empréstimo. Esta última é a mais utilizada. Todavia, sua utilidade é limitada na medida em que ela simplifica a apropriação de um modelo ou de uma reforma. Habitualmente, ela esquematiza a natureza da transferência e subestima a especificação das políticas educacionais e sua dependência dos contextos político, econômico e cultural do país (PHILLIPS, 1992).

Como sublinha Finegold, McFarland e Richardson (1992, p. 10): "Beyond the normal academic exercise of studying the influence of one country's policies on another. We are now interested in knowing both why countries borrow and what the domestic effects of such borrowing might be."”

2 “[...] no qual o conhecimento sobre as políticas, os processos administrativos, instituições etc. em um tempo ou lugar é usado no desenvolvimento de políticas, processos administrativos e instituições em um outro tempo ou lugar".

3 "Além do exercício acadêmico normal de estudar a influência das políticas de um país sobre o outro. Estamos agora interessados em saber porque alguns países as tomam emprestadas e quais os efeitos domésticos que tais empréstimos podem representar." 
Phillips (2000) propõe um modelo de transferência composto de sete estágios (acumulação, incubação, assimilação, tradução, contextualização, refração e resolução):

[...] a seven stage model of policy borrowing or importation is posited. For convenience, the stages are labeled as: accumulation, incubation, assimilation, translation, contextualisation, refraction and resolution. Accumulation refers to the apparently willy-nilly activity of gathering ideas by people who may be able to plant them in the policy arena at the right time. Incubation refers to the phase when ideas or policies begin to enter the realm of the decision-makers, as possible favoured alternatives, but have not yet been absorbed by the government. Assimilation encompasses the emergence, possibly as a consequence of competition among different alternatives, of a favoured option, as stated in official policy documents, while translation relates to the filling out of the details of the policy as an agenda for action. Contextualisation refers to the enactment of the new policy, and its attempted integration into the adopted or local context. Refraction denotes the consequences of the policy's attempted contextualisation, such as resistance, and how challenges to the policy are responded to, including possible alterations to the policy. Finally, resolution refers to the integration of the imported policy within its new environment, although this may not happen as originally envisaged and could even include abandonment of the imported policy in favour of another option. ${ }^{4}$

4 [...] um modelo de sete estágios de política de empréstimo ou importação é colocado. Por conveniência, os estágios são denominados como: acumulação, incubação, assimilação, translação, contextualização, refração e resolução. Acumulação se refere à aparentemente vacilante atividade de recolher idéias por meio de pessoas que se mostrem habilitadas a plantá-las na arena de políticas no momento adequado. Incubação se refere à fase quando as idéias ou políticas começam a entrar na esfera daqueles que tomam as decisões, como possíveis alternativas a serem favorecidas, mas não foram ainda absorvidas pelo governo. Assimilação abrange a emergência, possivelmente como uma conseqüência da competição entre diferentes alternativas, de uma opção favorecida, conforme estabelecida por documentos oficiais de políticas, enquanto translação se relaciona ao preenchimento dos detalhes da política no sentido de convertê-la em uma agenda de ação. Contextualização se refere à regulamentação da nova política e à tentativa de integrá-la no local de adoção ou contexto local. Refração denota as conseqüências da tentativa de adequação da política, tais como as resistências, e como as mudanças na política recebem resposta, incluindo a possível alteração na política. Finalmente, resolução se refere à integração da política importada dentro do novo ambiente, muito embora possa ter acontecido como originalmente fora prevista e que possa mesmo incluir o abandono da política importada em favor de uma outra. 
Como mostra um projeto de pesquisa em curso sobre a transferência dos modelos do ensino secundário (PEREZ, 2003), numerosos países do Sul tentam se inspirar na experiência dos países do Norte. Essa inspiração, por sua vez, remonta à época colonial e se baseia em particular sobre três afirmações:

- O ensino secundário contribui no crescimento econômico.

- O ensino secundário deve ser adaptado ao mercado de trabalho.

- O ensino secundário técnico é uma prioridade.

A primeira afirmação mostra o momento do avanço da experiência dos países do sudoeste asiático como pertinente e ser imitada. Ora, esquecemos freqüentemente que essa experiência é particular e supõe uma visão dialética da relação economia-educação. Investir no ensino secundário sem um desenvolvimento econômico dos setores industriais é estéril. A segunda afirmação é igualmente contestável na medida em que ela supõe uma presença reguladora do Estado nos dois setores (ensino secundário e mercado de emprego). Se esse modelo de adequação do ensino secundário/mercado de trabalho funcionou na Europa, notadamente nos anos 1950, 1960 e 1970, é porque o Estado teve meios para regulá-lo. Atualmente a situação é diferente, tanto nos países do Norte quanto nos países do Sul. A privatização crescente da atividade econômica e o desenvolvimento do ensino secundário privado limitam as possibilidades de uma adequação. A terceira formação clama por um desenvolvimento do ensino técnico como um elemento para a industrialização dos países do Sul. De um lado, o ensino técnico, que é o mais eficiente nos países do Norte, está baseado sobre o princípio da alternância (escola/empresa). Esse modelo que funciona em particular na Alemanha e na Suíça se baseia em uma longa tradição histórica e supõe que as empresas assumam e aceitem seu papel formador. Desenvolver o ensino técnico nos países do Sul segundo esse modelo de alternância é, portanto, difícil. De outro lado, é preciso relativizar a capacidade do ensino técnico em formar profissionalmente os jovens nos países do Sul. Essa formação, no local de trabalho ou em empresas, parece dar resultados mais convincentes.

Os países do Sul são confrontados com o desafio de melhorar seu sistema educacional, sendo submetidos a restrições externas (globalização) e dispondo de pouco tempo com relação àquele utilizado pelos países do Norte. Historicamente, é preciso lembrar, com efeito, que a Europa não tinha esse modelo e que ninguém lhe impunha tal modelo, uma vez que 
ela tinha um autofinanciamento de seu sistema educacional, no fim do século XIX e durante o século XX. A Europa construiu as soluções para suas dúvidas, tomando emprestado de uma reforma para outra à medida que os problemas se apresentavam no ensino secundário. Como o canal de internacionalização das políticas educacionais, a globalização e a cooperação em matéria de educação, os países do Sul importam modelos, nem sempre compatíveis com seus contextos econômico, social e cultural. Se, na Europa, a classe dirigente tinha tido tempo de tomar uma posição, nesse novo modo de reprodução social (a escolarização em massa), nos países do Sul, em contrapartida, a progressão aconteceu sem uma medida comum, uma vez que os efetivos do secundário explodiram durante um curto período. Foi assim em Marrocos, o país menos avançado em matéria de escolarização secundária. No Maghreb, a taxa de escolaridade no secundário passou de 0,3 a 28\% entre 1955 e 1985 (VERMEREN, 2002). Os países do Sul conheceram, de forma concomitante, muitos fenômenos que a Europa tinha exibido por mais de um século e meio: adesão da classe dominante ao novo sistema de meritocracia, conquista dos estabelecimentos secundários para os "os filhos da elite" e "massificação" do ensino secundário.

\section{EM DIREÇÃo A UM ENSINO SECUNDÁRIO COM VÁRIOS RITMOS OU UMA PROFISSIONALIZAÇÃO MAIOR DO CORPO DE EDUCADORES}

A educação secundária continua estendendo-se rapidamente em nível mundial. Mais de um bilhão e meio de estudantes se matricularam nas escolas secundárias em 2004, um aumento de mais de 60 milhões em apenas cinco anos (UNESCO, 2007). Mas esse aumento de importância do ensino secundário está gerando crises.

Charlot (1987) distingue três tipos de crise: a crise como ruptura do equilíbrio, como resistência à modernidade e como exarcebação das contradições sociais. Segundo Charlot (1987, p. 28), “[...] le premier concept pose que lorsque l'équilibre d'un système est rompu, ce système subit un malaise, un trouble, un ébranlement qui perturbe son fonctionnement et sa reproduction. Le désordre s'installe, des tensions apparaissent: le système est en crise". ${ }^{5} \mathrm{Na}$ direção que o sistema em questão tomará, em seus

5 “[...] o primeiro conceito diz que o equilíbrio de um sistema é rompido, esse sistema sofre um mal-estar, um problema, um abalo que perturba seu funcionamento e sua reprodução. A desordem se instala, as tensões surgem: o sistema está em crise." 
aspectos estatísticos ou em movimento dinâmico, o tipo de crise passará, seja por uma ou outra forma de "restauração" do antigo estado, seja por uma adaptação às novas realidades. Enquanto que na resistência à modernidade, a crise aparece como "[...] due aux rigidités, aux blocages, qui s'expriment dans la société à travers les corporatismes de toutes sortes. Les interprétations de la crise de l'école en termes d'archaïsme, de routine, de pétrification des structures, de corporatisme enseignant, relèvent de ce mode de pensée" (CHARLOT, 1987, p. 30). ${ }^{6}$ O tipo de crise que passa pela renovação, inovação e mudança, seja qual for o tipo de definição que encarna o progresso.

Finalmente, como exacerbação das contradições sociais, a crise parece indissociável da vida social, pois todo o sistema social trabalha sempre pelas contradições, por pontos de vista múltiplos e articulados entre eles, mas não reduzíveis a somente um. Aqui não há cenário predefinido de tipo de crise: há somente os grupos e as forças que escrevem a história nas suas confrontações.

Podemos dizer que o ensino secundário nos países do Sul está atravessando três tipos de crise, identificadas por Charlot. Primeiramente, trata-se de uma crise de ruptura de equilíbrio. Com efeito, o crescimento rápido dos efetivos exerce uma forte pressão sobre as infra-estruturas escolares e o mercado de trabalho. Em numerosos países, os Estados transformam precipitadamente as escolas primárias em escolas secundárias. Os diplomas do ensino secundário exercem igualmente uma pressão sobre o ensino superior. No Brasil, por exemplo, esse fenômeno provocou o crescimento exponencial do ensino particular (AKKARI, 1999).

Em seguida, o ensino secundário está atravessando uma crise de modernidade. Com efeito, ocorre a terceirização da economia, da sociedade, do conhecimento e, ao mesmo tempo, das estruturas e dos programas de ensino secundário ultrapassados. Mas as transformações são lentas e atingem os corporativismos. A função pública de ensino tem dificuldade em aceitar essas novas realidades educacionais.

Enfim, e é este provavelmente o mais importante, pois reencontramos este aspecto ao mesmo tempo nos países do Sul e do Norte,

6 “[...] devido à rigidez, a bloqueios, que se exprimem na sociedade através dos corporativismos de todos os tipos. As interpretações da crise da escola em termos de arcadismo, de rotina, de petrificação das estruturas, de cooperativismo do ensino, dão origem a esse modo de pensamento". 
o ensino secundário exprime uma exacerbação das contradições sociais. Certamente, o ensino secundário, em particular no primeiro ciclo, deve se tornar um lugar da aprendizagem, do viver junto dos alunos para além dos seus laços sociais e culturais. Ele tem também um papel de democratizar os estudos. Para outros, ao contrário, o ensino secundário deve diferenciar o mais cedo possível as seções escolares, a fim de permitir a circulação dos estudantes, conforme vias paralelas. Por detrás do plano dessa oposição, há o debate pedagógico sobre a necessidade de um ensino secundário centrado na "socialização" ou um ensino secundário centrado sobre "o conteúdo" e sobre as disciplinas escolares (o movimento de retorno ao essencial, nos países anglo-saxões). Em relação à evolução do ensino secundário, Lessard e Tardif (2001) delineiam três cenários, apoiando-se nos estudos realizados nos países do Norte: a restauração nostálgica do modelo canônico e das desigualdades, a tomada de controle dos empresários tecnófolos e a marcha prudente, mas aberta, das organizações de aprendizes e profissionais.

Esses três tipos de crise produzem as condições para um ensino secundário em vários ritmos. Em todo o ensino secundário é recolocada em questão a importância das taxas de repetência e de fracasso das aquisições de uma parte dos alunos, disponibilizada em evidência pelas pesquisas internacionais. As tensões entre, de uma parte, um ensino secundário, tendo por finalidade desenvolver a cultura geral de transmitir valores e preparar os futuros cidadãos, e, de outra parte, um ensino secundário encarregado de transmitir os conhecimentos, os padrões de qualidade, um currículo nacional, a aprendizagem das línguas.

Como sublinha Moreno Olmedilla (2006), o professorado qualificado do ensino secundário está se convertendo em um bem escasso em muitos países subdesenvolvidos ou em desenvolvimento. Essa parte do corpo docente é aquela que é mais dificilmente atraída para a profissão, aquela cuja formação séria custa mais e aquela que é mais difícil reter nos centros educacionais. $\mathrm{O}$ número de professores não qualificados pode ser muito mais elevado no ensino secundário do que no primário, no caso de todos os países em desenvolvimento. A taxa de deserção profissional no secundário é a mais elevada da profissão docente, sobretudo no caso de professores do sexo masculino e nas áreas curriculares de maior demanda, como matemática, ciências e tecnologia (OCDE, 2005). Nesse difícil contexto, esse trabalho parte da idéia de que existe um profundo - e talvez crescente - desajuste entre as novas competências-chave que se 
exigem dos graduados da educação secundária na sociedade do conhecimento e as competências docentes com que são "equipados" os professores do secundário após sua passagem pela universidade e, nesse caso, escolas profissionais de formação docente. Em um cenário que aponta a democratização da educação secundária em todo o mundo, até alcançar em muitos países caráter universal já neste momento, tal desajuste se apresenta como a principal limitação cuello de botella para a expansão da educação secundária de qualidade.

\section{Conclusão}

A massificação do ensino secundário parece inevitável. Com efeito, se os processos em curso tanto no Norte como no Sul são da mesma natureza, os ritmos e as modalidades precisam se diferenciar de um contexto para o outro. Essa progressão do ensino secundário parece funcionar conforme o esquema seguido nos países do Sul. Uma vez realizada a universalização do ensino primário, constatamos um esforço maior para, ao mesmo tempo, aumentar a escolaridade obrigatória, mas também desenvolver o acesso ao ensino secundário. Os países emergentes, que realizaram a universalização nos anos 1960, estão acima dos países da OCDE em termos de escolaridade no ensino secundário. Mas o esforço financeiro será colossal e necessitará de uma clara vontade política para considerar a educação como a prioridade das prioridades. Ao mesmo tempo, essa massificação não é equivalente a uma democratização.

O ensino secundário funciona sempre sob uma lógica de diferenciações interna e externa. A diferenciação interna ao sistema educativo consiste em oferecer o acesso ao ensino secundário diversificando e classificando seções escolares. As categorias sociais desfavorecidas e as minorias étnicas se encontram claramente nas seções com poucas exigências escolares. A diferenciação externa ao sistema escolar público opera através das desigualdades territoriais e de recursos ao ensino particular ou a tutores privados. Em numerosos países, onde o sistema de ensino público se apresenta como unitário e nacional, as desigualdades territoriais foram menos evidentes. $\mathrm{O}$ recurso ao ensino privado e o turismo escolar reforça as desigualdades territoriais. Por outro lado, o recurso para as famílias e os serviços educacionais privados complementares ao serviço público permitem reforçar a diferenciação dos setores de ensino secundário. 
Uma diferença importante entre o Norte e o Sul é o aumento da frustração acumulada pelos diplomados do ensino secundário. Com efeito, nos países do Sul, uma minoria deles pode pretender prosseguir com seus estudos superiores ou se inserir no mercado de trabalho. Nos países do Norte, essa situação é mais dramática e atinge mais particularmente os filhos de imigrantes e de minorias étnicas.

\section{REFERÊnCIAS}

AKKARI, A. Inégalités éducatives structurelles au Brésil: entre état, rivatisation et écentralisation. Carrefours de l'Éducation, v. 8, p. 140-162, 1999.

BAUDELOT, C.; ESTABLET, R. L'école capitaliste en France. Paris: Maspéro, 1971. BIHR, A.; PFEFFERKORN, R. Déchiffrer les inégalités. Paris: Syros, 1995.

CHARLOT, B. L'école en mutation. Paris: Payot, 1987.

CHARLOT, B.; BAUTIER, E.; ROCHEX, J. Y. Ecole et savoir dans les banlienes... et ailleurs. Paris: Armand Colin, 1992.

CHARLOT, B. O conflicto nasce quando o professor não ensina. Nova Escola, p. 15-18, out. 2006.

DOLOWITZ, D.; MARSH, D. Who learns what from whom?: a review of policy transfer literature. Birmingham: University of Birmingham, 1996.

FINEGOLD, D.; McFARLAND, L.; RICHARDSON, W. Something borrowed, something blue? A study of the Thatcher Government's appropriation of American education and training policy, parts 1-2. Oxford Studies in Comparative Education, v. 2-3, 1992/1993.

ISAMBERT JAMATI, V. Quelques aspects de l'émergence de l'échec scolaire comme "problème social" dans les milieux pédagogiques français. In: PLAISANCE, E. (Ed.). L'échec scolaire, nowveaux débats, nouvelles approches sociologiques. Paris: Editions du CNRS, 1985. p. 155-163.

LESSARD, C.; TARDIF, J. Les transformations actuelles de l'enseignement: trois scénarios possibles dans l'évolution de la profession enseignante. Education et Francophonie, v. 29, n. 1, 2001. Disponível em: < http://www.acelf.ca/revue/XXIX1/articles/04-Lessard-Tardif.html\#h-4>.

MORENO OLMEDILLA, J. M. Profesorado de secundaria y calidad de la educación: un marco de opciones políticas para la formación y el desarrollo profesional docente. Profesorado. Revista de Curriculum y Formación del Profesorado, v. 10, n. 1, 2006.

OCDE. Attracting, developing and retaining effective teachers. Paris: OCDE, 2005.

PEREZ, S. Transferts des modèles d'enseignement secondaire dans les pays du Sud. Genève: UNESCO/BIE. Faculté de Psychologie et des Sciences de l'Éducation, 2003. 
PHILLIPS, D. Borrowing education policy. Oxford Studies in Comparative Education, v. 2, n. 2, 1992.

Policy importation and the development of the national qualifications framework. In: AARE-NZARE CONFERENCE, Melbourne, nov./Dec. 2000. ROSE, R. What is lesson drawing? Journal of Public Policy, 11, p. 3-30, 1991.

THIN, D. Quartiers populaires, l'école et les familles. Lyon: Presses Universitaires de Lyon, 1998.

UNESCO. Strong foundations: early childhood care and education. Paris: UNESCO, 2007.

UNESCO-ISU/OCDE. Financing education - investment and returns: analysis of the world education indicators. Paris: UNESCO-ISU/OCDE, 2003.

VERMEREN, P. La formation des élites marocaines et tunisiennes. Des nationalistes aux islamistes, 1920-2000. Paris: La Découverte, 2002.

(Tradução: Natania A. S. Nogueira)

Recebido em: 05/10/2006

Aprovado em: 13/11/2006 